\title{
Comparative analysis of aluminium surface roughness in end-milling under dry and minimum quantity lubrication (MQL) conditions
}

\author{
Ugochukwu C. Okonkwo ${ }^{1, *}$, Imhade P. Okokpujie ${ }^{1}$, Jude E. Sinebe ${ }^{1}$, and Chinedu A.K. Ezugwu ${ }^{2}$ \\ 1 Department of Mechanical Engineering, Nnamdi Azikiwe University, PMB 5025 Awka, Nigeria \\ 2 Department of Mechanical Engineering, Landmark University, PMB 1001 Omu-Aran, Kwara, Nigeria
}

Received 31 July 2015 / Accepted 17 November 2015

\begin{abstract}
In this study an experimental investigation of effects of cutting parameters on surface roughness during end milling of aluminium 6061 under dry condition and minimum quantity lubrication (MQL) condition were carried out. Spindle speed $(N)$, feed rate $(f)$, axial depth of cut $(a)$ and radial depth of cut $(r)$ were cutting parameters chosen as input variables in the investigation of the surface roughness quality. The experimental design adopted for this study was the central composite design (CCD) of response surface methodology. Thirty samples were run in a CNC milling machine for each condition and the surface roughness measured using Mitutoyo surface tester. A comparison showing the effects of cutting parameters on the surface roughness for dry and MQL conditions in end-milling of aluminium were evaluated. Surface roughness values for MQL condition were lower with up to $20 \%$ reduction when compared to dry conditions. MQL cutting condition was found to be better and more reliable because it is environmentally friendly and gives better surface finish. With the obtained optimum input parameters for surface roughness, production operations will be enhanced.
\end{abstract}

Key words: Surface roughness, Minimum quantity lubrication (MQL), CNC end milling, Response surface methodology

\section{Introduction}

The quality of machined surface is characterized by the accuracy of its manufacture with respect to the dimensions specified by the designer. Every machining operation leaves characteristic evidence on the machined surface. This evidence in the form of finely spaced micro irregularities left by the cutting tool. Each type of cutting tool leaves its own individual pattern that therefore can be identified. This pattern is known as surface finish or surface roughness. The surface roughness of a machined surface depends on many factors and can be grouped as follows:

- Geometric factors which are the type of machining operation, the cutting geometry and the feed.

- Work material factors which includes the built up edges effect, damaged to the surface caused by chip curling back into work, tearing of work surface during chip formation when machining ductile materials, friction between the tool flank and newly generated work surface etc.

*e-mail: ugocoons@yahoo.com
- Vibration and machine tool factors which are ones related to the machine tool, tooling and setup in operation.

The characteristic feature of the milling process is that each milling cutter tooth removes its share of the stock in the form of small individual chips. It is of three types which are: peripheral milling, face milling and end milling. End milling is one of the most common metal removal operation encountered in industrial process. It is widely used in the manufacturing industries which include the automotive and aerospace sectors, where quality is an important factor in the production of slots, pockets, precision molds, and dies. In end milling, the cutter generally rotates on an axis vertical to the work-piece. It can be tilted to machine tapered surfaces. Cutting teeth are located on both the end face of the cutter and the periphery of the cutter body.

The primary function of the MQL in metal machining operations is to serve as a coolant, also as a lubricant thereby reducing friction and tool wear. It is generally agreed that the application of MQL can improve the tool life and results in 
good surface finish by reducing thermal distortion and flushing away of machined chips. What is perhaps even more important is to ensure proper filtration of the fluid as suspended swarf can cause random deep scratches on the job. Obtaining a good surface quality is very important in every engineering component design or fabrication. Good surface finish influences mechanical properties such as fatigue behavior, wear, corrosion, lubrication, and electrical conductivity. Therefore measurement of surface finish and characterization also plays an important part in the prediction of a machining performance. One way to check if a machined material has good quality is through the measurement of its surface roughness (arithmetic average, $R_{\mathrm{a}}$ ).

The knowledge of tool and cutting parameters can stem from either pure experimental analysis or hybrid of experimental and numerical/theoretical analysis [1]. Matsubara et al. [2] developed a theoretical model for accuracy of end-milling by investigating the transfer matrix and instantaneous chip thickness leading respectively to derivation of the static stiffness of the end mill and the instantaneous cutting forces. Budak and Alintas [3] presented a model that highlighted dependence of surface accuracy on the cutting parameters. Insperger et al. [4] generated both the stability diagram and the surface location error diagram and discussed the selection of optimal spindle speed considering both diagrams. Surface roughness is the inherent irregularities left by a single-point tool like turning tool or milling tool on a machined surface. Surface roughness is noted by Field et al. [5] that surface roughness is predominantly considered as the most important feature of practical engineering surfaces due to its crucial influence on the mechanical and physical properties of a machined part.

The roughness of a machined surface is an indication of relative vibration between the tool and work piece during a machining operation as the work of Peigne et al. [6] in which they studied the effects of the cutting vibratory phenomena and their impacts on the surface roughness of the machined surface suggests. The parameters of machining process are expected to affect this relative vibration thus have effects on component surface roughness. The obvious machining parameters of a machining process such as end-milling are the cutting speed, the axial depth of cut, the radial depth of cut and the feed rate. These are the most easily controlled parameters of the machining process being at the disposal of the operator to choose or to vary continuously in process. Other parameters include tool geometry (given in terms of tool angles like rake angle, flank or tool relief angle, notch angle), tool and work piece material and tool wear. Tool wear being a tribological phenomenon develops with progression of machining and then causes progressive increase in surface roughness.

Surface roughness has been attributed to cutting conditions, tool geometry and mechanical stiffness. Various other studies have considered the behavior of surface roughness under different tool-work-piece material combinations and experiments. Kishawy et al. [7] studied the effect of flood coolant, and dry cutting, on tool wear, surface roughness and cutting forces. A study of the surface integrity produced by end mill tool using a Taguchi orthogonal array has been presented by Mantle and Aspinwall [8], Wang and Chang [9] analyzed the influence of cutting conditions and tool geometry on surface roughness of slot end milling operation. Feasibility study and development of an in-process based recognition system to predict the surface roughness of machined parts in the end milling process has been presented by Tsai et al. [10]. Similarly, Ertekin et al. [11] has identified the most influential and common sensory features for dimensional accuracy and surface roughness in $\mathrm{CNC}$ milling operations.

Ginta et al. [12] developed an effective methodology to determine the performance of uncoated WC-Co inserts in predicting minimum surface roughness in end milling of titanium alloys Ti-6Al-4V under dry conditions. Central composite design (CCD) of response surface methodology (RSM) was employed to create an efficient analytical model for surface roughness in terms of cutting parameters: cutting speed, axial depth of cut, and feed per tooth. End milling tests were conducted on Vertical Machining Center (VMC ZPS, Model: MLR 542) with full immersion cutting and under dry condition. They concluded with CCD being a successful technique to predict the surface roughness produced in end-milling of titanium alloy Ti-6Al-4V using uncoated inserts under dry conditions. Linear CCD model proved inadequate while quadratic CCD model was adequate with $95 \%$ accuracy. The two developed models indicated that feed was the most predominant cutting condition followed by cutting speed and depth of cut. Interaction effect between cutting speed and feed will also give a high effect on surface roughness values.

Arokiadass et al. [13] also studied the influence of four machining parameters including spindle speed $(N)$, feed rate $(f)$, depth of cut $(d)$, and various percentage weight of silicon carbide (S) on surface roughness $\left(R_{\mathrm{a}}\right)$. The RSM was employed to establish the mathematical relationship between the response and the various process parameters. The result they obtained showed that the quadratic model was statistically significant for analysis of surface roughness. Their model indicated that the feed rate was the most dominant parameter on surface roughness followed by spindle speed and \%weight of $\mathrm{SiC}$. Depth of cut has less influence on surface roughness. The effect of cutting parameters on surface roughness during end milling of aluminium under (MQL) was carried out by Okokpujie and Okonkwo [14]. The mathematical model developed by using least square approximation method shows accuracy of $89.5 \%$ which is reasonably reliable for surface roughness prediction.

\section{Materials and methods}

The work piece material used for the study was a rectangular 6061 aluminium blocks of $2000 \mathrm{~mm} \times 50 \mathrm{~mm} \times 5 \mathrm{~mm}$. Method used for the experimental investigations is explained thus:

- Preparation of the vertical CNC milling machine system ready for performing the machining operation, cutting of the work piece of the aluminium 6061 rectangle plate into different sizes of $10,15,20,25$ and $30 \mathrm{~mm}$. A total of 60 pieces, 30 pieces for the dry cutting condition and 30 pieces for MQL condition.

- Fixing of the high speed steel (HSS) end milling cutter of $12 \mathrm{~mm}$ diameter on the spindle taper of the machine. 


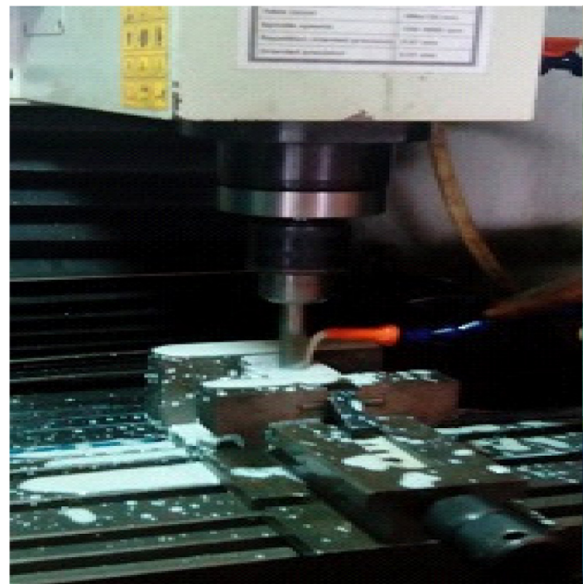

Figure 1. Experimental setup for MQL end milling operation.

- Mounting the work piece, clamped on a vice mounted on top of the table of the machine as shown in Figures 1 and 2 , respectively.

- Creating CNC part programs on CNC professional software for tool paths, with specific commands using different factor levels of spindle speed, feed rate, axial depth of cut and radial depth of cut, taking reference for $Y$ axis, and $Z$ axis then performing end milling operation.

- After each machining the surface roughness of the work piece was measured with the press-o-firm and Mitutoyo surface tester.

Detailed information on chemical composition of the 6061 aluminium is provided in Table 1 , and details of the experimental outlay in Table 2, only up-milling cutting mode was investigated.

The experiment was performed on SIEG 3/10/0016 and SIEG 3/10/0010 table top CNC machine vertical milling centre. The vertical milling centre has three (3) planes namely $x, y$ and $z$ planes. The experimental set up is shown in Figures 1 and 2.

Second-order rotatable central composite design of response surface methodology (RSM) was employed in the experimental design. RSM is a collection of mathematical and statistical techniques for empirical model building. By careful design of experiments, the objective is to optimize a response (output variable) which is influenced by several independent variables (input variables). An important aspect of RSM is the design of experiments. A second-order model can be constructed efficiently with central composite designs (CCD). CCD are first-order $\left(2^{N}\right)$ designs augmented by additional centre and axial points to allow estimation of the tuning parameters of a second-order model. By considering all the factorial corner points, some of the central replicates and all the axial points second-order rotatable central composite design requires between 25 and 33 experimental runs depending on the number of the central replicates considered while a full factorial design will require $5^{4}=625$ experimental runs. This explains the choice of second-order rotatable central composite design which tremendously reduces needed number of

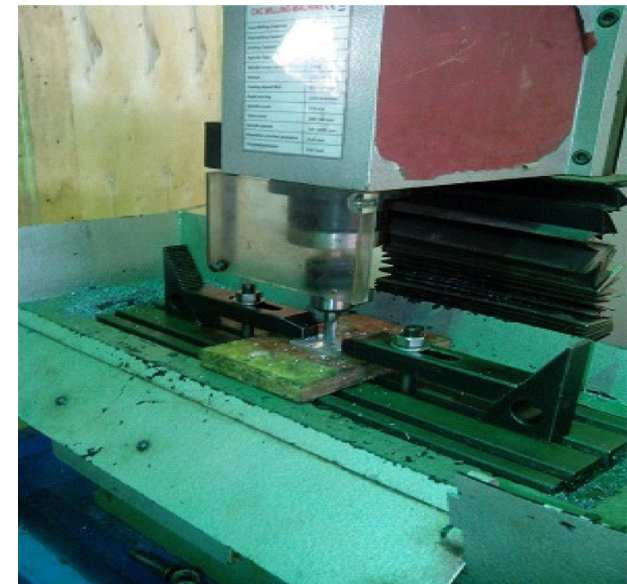

Figure 2. Experimental setup for dry end milling operation.

Table 1. Chemical composition of Al-6061.

\begin{tabular}{lcccccccc}
\hline Element & $\mathrm{Mg}$ & $\mathrm{Fe}$ & $\mathrm{Si}$ & $\mathrm{Cu}$ & $\mathrm{Mn}$ & $\mathrm{V}$ & $\mathrm{Ti}$ & $\mathrm{AL}$ \\
\hline Weight \% & 1.08 & 0.17 & 0.63 & 0.32 & 0.52 & 0.01 & 0.02 & Remainder \\
\hline
\end{tabular}

experimental runs for the MQL cutting conditions, which doubles the calculated number of experimental runs. The design expert 9.0.1 was used in analysis and presentation of results.

The response surface methodology (RSM) is the procedure for determining the relationship between the independent process parameters with the desired response and exploring the effect of these parameters on responses, including six steps. These are in the order:

- Define the independent input variables and the desired responses with the design constants.

- Adopt an experimental design plan.

- Perform regression analysis with the quadratic model of RSM.

- Calculate the statistical analysis of variance (ANOVA) for the independent input variables in order to find which parameter significantly affects the desired response.

- Determine the situation of the quadratic model of RSM and decide whether the model of RSM needs screening variables or not.

- Optimize and conduct confirmation experiment and verify the predicted performance characteristics.

The experimental plan was developed to assess the influence of spindle speed $(N)$, feed rate $(f)$, axial depth of cut $(a)$ and radial depth of cut $(r)$ on the surface roughness parameters $\left(R_{\mathrm{a}}\right)$. Five levels were allocated for each cutting variable as given in Table 3 . The variable levels were chosen within the intervals recommended by cutting tool manufacturer. Four cutting variables at five levels led to a total of 30 tests for each condition.

The required number of experimental points for four-factor in the CCD with one replication of factorial and axial parts having, factorial design is $=2^{f}=2^{4}=16$, the axial point or 
Table 2. Details of the experimental outlay.

\begin{tabular}{lccccc}
\hline Exp. runs & Material & MQL cutting condition & Cutting tool & Input parameters & Response parameters \\
\hline 1 to 30 & Al-6061 alloy & $\begin{array}{c}10 \% \text { boric acid }+ \\
\text { base oil SAE } 40\end{array}$ & High speed steel & $\begin{array}{c}\text { Cutting speed, feed rate, axial depth of cut } \\
\text { and radial depth of cut }\end{array}$ & Surface roughness \\
\hline
\end{tabular}

Table 3. Factor levels to be used in the experimental design.

\begin{tabular}{lccccc}
\hline Variable & \multicolumn{5}{c}{ Levels } \\
\cline { 2 - 6 } & -2 & -1 & 0 & 1 & 2 \\
\hline Spindle speed [rpm] & 1000 & 1500 & 2000 & 2500 & 3000 \\
Feed rate [mm/min] & 100 & 150 & 200 & 300 & 500 \\
Radial depth of cut [mm] & 0.5 & 1 & 1.5 & 2.0 & 2.5 \\
Axial depth of cut [mm] & 10 & 15 & 20 & 25 & 30 \\
\hline
\end{tabular}

Table 4. Standard experimental matrix for the factorial design, star point and center points for CCD for both dry and MQL conditions.

\begin{tabular}{|c|c|c|c|c|}
\hline \multirow[t]{2}{*}{ Exp. no } & \multicolumn{4}{|c|}{ Coded value } \\
\hline & $x_{1}$ & $x_{2}$ & $x_{3}$ & $x_{4}$ \\
\hline 1 & -1 & -1 & -1 & -1 \\
\hline 2 & 1 & -1 & -1 & -1 \\
\hline 3 & -1 & 1 & -1 & -1 \\
\hline 4 & 1 & 1 & -1 & -1 \\
\hline 5 & -1 & -1 & 1 & -1 \\
\hline 6 & 1 & -1 & 1 & -1 \\
\hline 7 & -1 & 1 & 1 & -1 \\
\hline 8 & 1 & 1 & 1 & -1 \\
\hline 9 & -1 & -1 & -1 & 1 \\
\hline 10 & 1 & -1 & -1 & 1 \\
\hline 11 & -1 & 1 & -1 & 1 \\
\hline 12 & 1 & 1 & -1 & 1 \\
\hline 13 & -1 & -1 & 1 & 1 \\
\hline 14 & 1 & -1 & 1 & 1 \\
\hline 15 & -1 & 1 & 1 & 1 \\
\hline 16 & 1 & 1 & 1 & 1 \\
\hline 17 & -2 & 0 & 0 & 0 \\
\hline 18 & 2 & 0 & 0 & 0 \\
\hline 19 & 0 & -2 & 0 & 0 \\
\hline 20 & 0 & 2 & 0 & 0 \\
\hline 21 & 0 & 0 & -2 & 0 \\
\hline 22 & 0 & 0 & 2 & 0 \\
\hline 23 & 0 & 0 & 0 & -2 \\
\hline 24 & 0 & 0 & 0 & 2 \\
\hline 25 & 0 & 0 & 0 & 0 \\
\hline 26 & 0 & 0 & 0 & 0 \\
\hline 27 & 0 & 0 & 0 & 0 \\
\hline 28 & 0 & 0 & 0 & 0 \\
\hline 29 & 0 & 0 & 0 & 0 \\
\hline 30 & 0 & 0 & 0 & 0 \\
\hline
\end{tabular}

where $x_{1}=$ spindle speed $(\mathrm{rpm}), x_{2}=$ feed rate $(\mathrm{mm} / \mathrm{min})$, $x_{3}=$ axial depth of cut $(\mathrm{mm}), x_{4}=$ radial depth of cut $(\mathrm{mm})$.

star point is $=2 \times f=2 \times 4=8$, where $f=$ number of factors, the center point chosen for this experiment is 6 , which is $=16+8+6=30$. Therefore the thirty experiments are carried out according to the blocked central composite design (CCD).
The experimental plan gave rise to the second order polynomial model by applying multiple regression analysis. The experimental matrix for the factorial design, star point and center points are shown in Table 4.

\section{Results}

\subsection{Comparisons between surface roughness for dry and MQL condition}

Table 5 shows the results of the experiments for the various cutting parameters and measured Ra values for the end milling of aluminium under dry cutting condition (column 7), MQL condition (column 8) and percentage reduction in surface roughness (column 9). A total of 60 experiments were carried out 30 for dry condition and 30 for MQL condition. The coded values of Table 4 have been replaced with the actual values.

The concept of MQL is a precise solution in achieving reduced tool wear and good surface finish as well as long tool life while maintaining cutting force and power at reasonable level. MQL not only reduces tool wear, tool life and surface finish, but reduces the waste involved in conventional application of cutting fluid. Table 5 shows the comparison between the surface finish obtained in dry and MQL condition. It can be seen that there was a significant improvement in the surface finish of about a maximum of $20 \%$ which is shown in the reduction in the average surface roughness value of the testing data.

The results in Table 5 which were clearly depicted in Figure 3 for surface roughness generally show that application of MQL greatly improves the surface finish when compared with dry cutting condition, all other advantages notwithstanding. It can be seen that a reduction of up to $20 \%$ surface roughness value can be obtained in the machining of aluminium in end milling processes by the application of MQL. These findings were in line with observations made by Abhang and Hameedullah [15] in a related study. The comparison between dry and MQL machining environment is show in Figure 13. Besides, there is more efficient penetration of fluid into the cutting region, which is environmentally friendly, and cause less pollution. This means that machining in MQL environment leads to a better surface finish and less hazardous environment.

\subsection{Effects of cutting parameters on surface roughness in dry and MQL conditions}

The effects of cutting parameters on surface roughness in end milling of aluminium were investigated using contour plots of the results obtained in dry and MQL conditions. The graphical evaluation was obtained by plotting surface roughness values against the various cutting parameters (axial depth 
Table 5. Experimental results of surface roughness of dry and MQL condition.

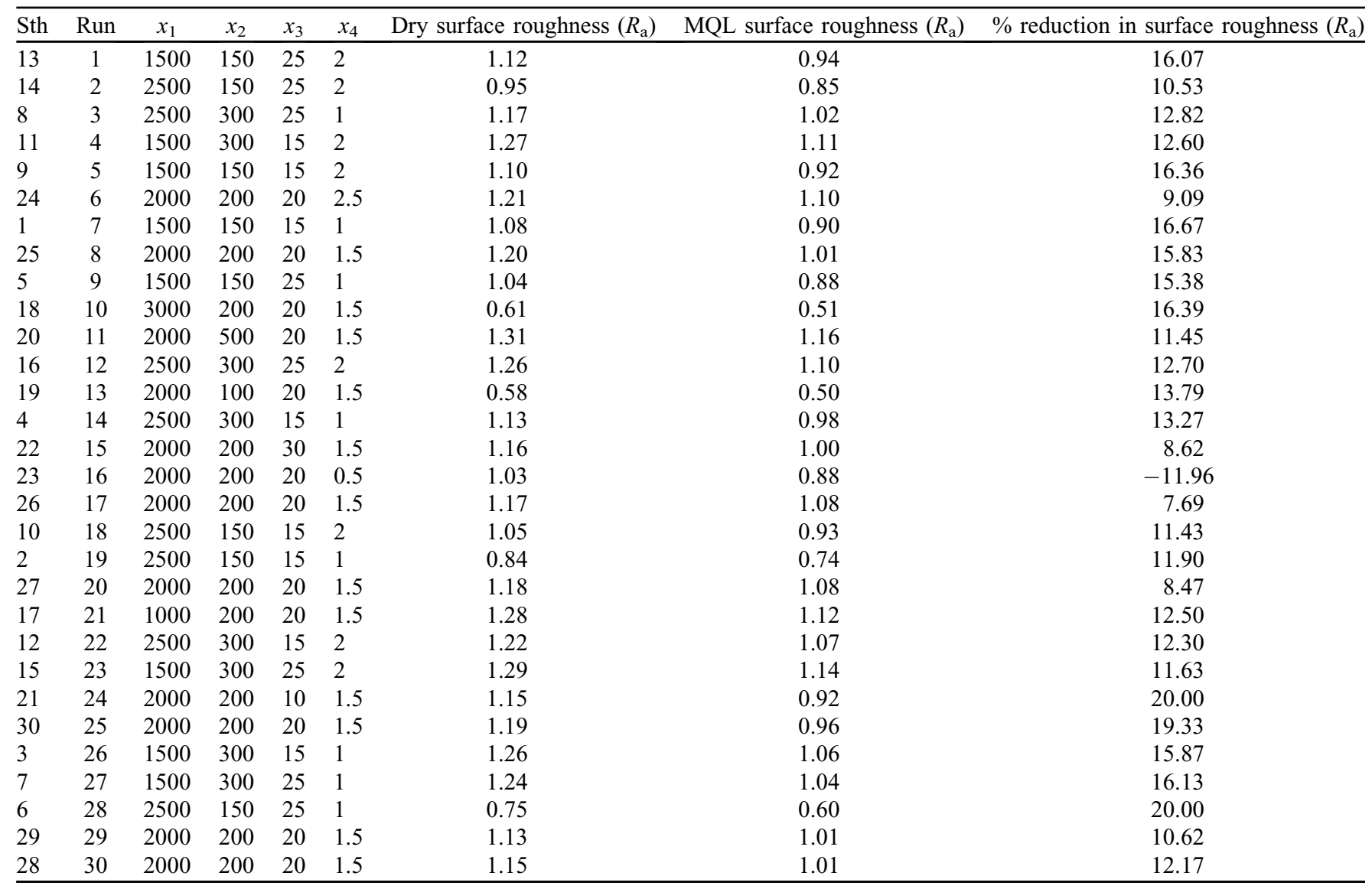

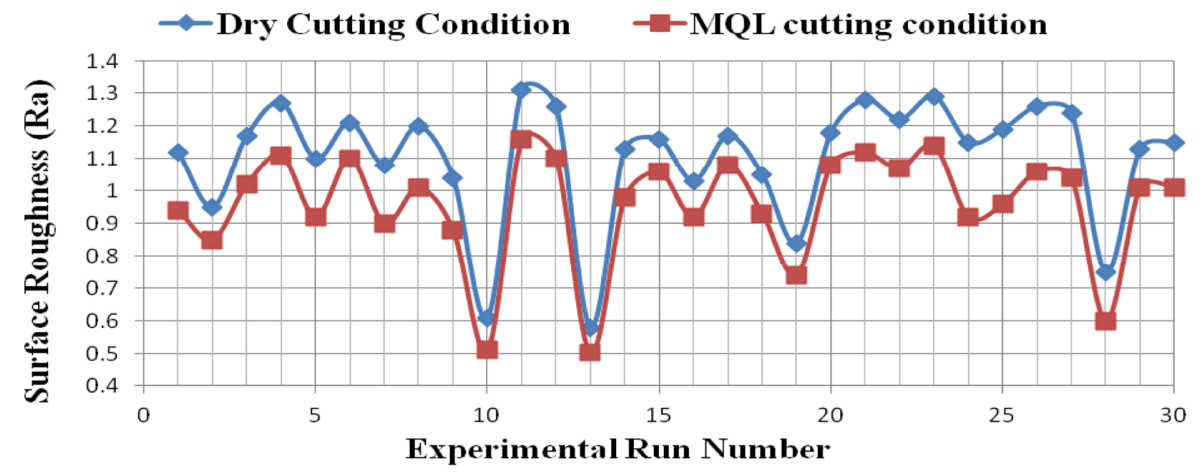

Figure 3. Comparisons between surface roughness for dry and MQL condition.

of cut, radial depth of cut, spindle speed and feed rate). Surface roughness values were simultaneously plotted against two cutting parameters while keeping the other two constant. Figures 4-13 show the experimental results obtained from the effect of cutting parameters on surface roughness.

\section{Effects of spindle speed and feed rate on surface roughness}

Figures 4 and 5 show the surface roughness contour plots of spindle speed versus the feed rate in dry and MQL, respectively. At each instance, the axial depth of cut and radial depth of cut were kept at $25 \mathrm{~mm}$ and $2 \mathrm{~mm}$.
It can be seen from the Figures 4 and 5 that there is indeed an interaction which has a nonlinear relationship on the surface roughness. Specifically, at spindle speed of $1500 \mathrm{rpm}$ and feed rate of $150 \mathrm{~mm} / \mathrm{min}$, the surface roughness obtained during dry condition was $1.12 \mu \mathrm{m}$ while that for the MQL condition was $0.94 \mu \mathrm{m}$. The highest surface roughness of the dry condition revolves around $1.31 \mu \mathrm{m}$ while that of the MQL condition revolves around $1.16 \mu \mathrm{m}$ as shown in Figures 4 and 5, respectively. A surface roughness as low as 0.58 and 0.50 can be obtained from dry and MQL condition and these region is at the down-left side of the two figures. On a general note, increasing the spindle speed reduces the surface roughness. 


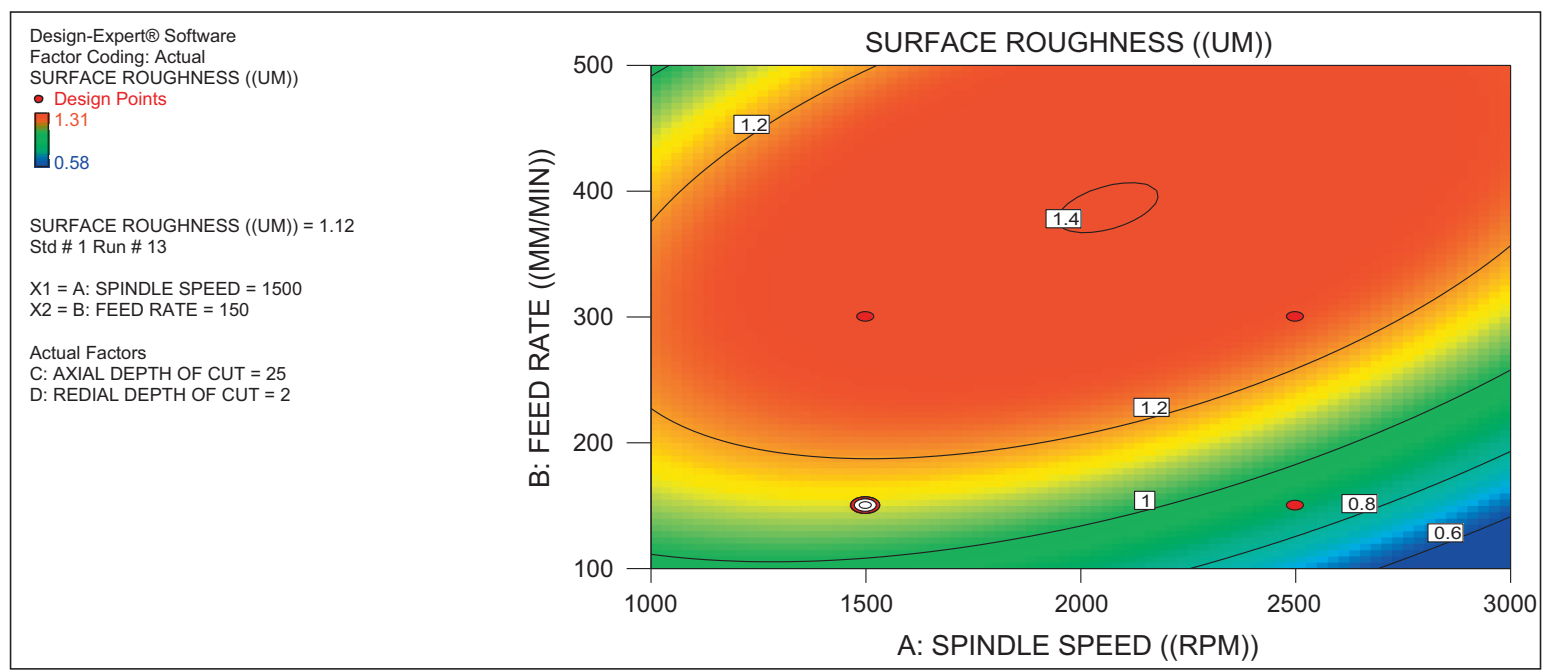

Figure 4. Surface roughness contour plot for spindle speed vs. feed rate in dry condition.

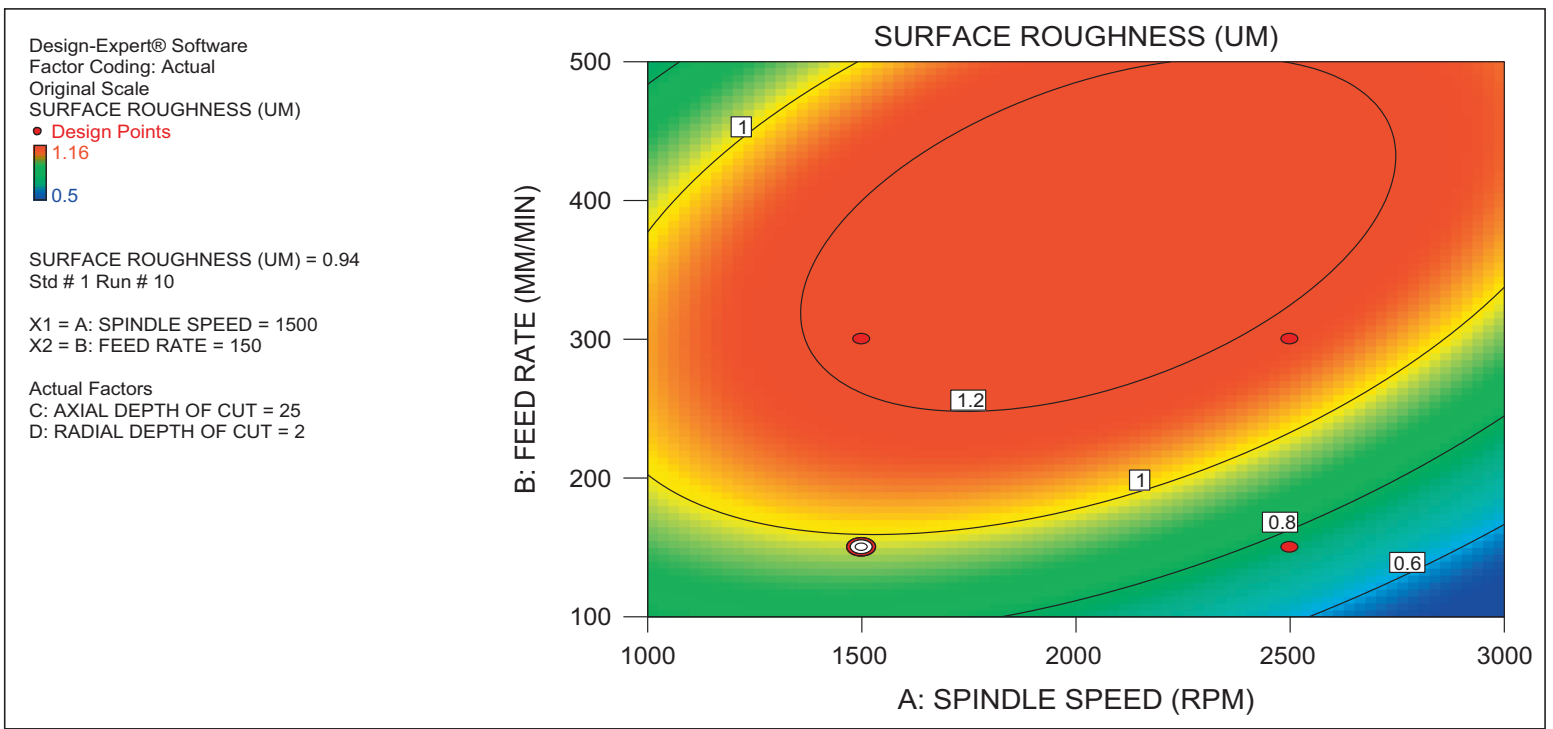

Figure 5. Surface roughness contour plot for spindle speed vs. feed rate in MQL condition.

Apparently, increasing the spindle speed increases the cutting force and eliminates the built-up edge (BUE) tendency. At low spindle speed (rpm), the unstable larger BUE is formed and also the chips fracture readily producing the rough surface. As the spindle speed (rpm) increases, the BUE vanishes, chip fracture decreases, and hence, the roughness decreases. These findings were in line with observations made by Tosun and Huseyinoglu [16]; Korkut and Donertas [17] in related studies.

In this investigation it was also observe that an increase in feed rate significantly increases the surface roughness. Increasing feed rate increases vibration and heat generated, which courses an increase in surface roughness. As the feed rates were increased, chips become discontinuous and were deposited between work piece and tool leading to increased coefficient of friction and more interruption resulting in poor surface finish. In MQL environment, due to the lubricating effect at cutting zone during machining, friction between work piece and tool was reduced, consequently, the surface roughness values were reduced when compared with dry condition. This results corresponds to the result obtained by Arokiadass et al. [13] in his research on predictive modeling of surface roughness in end milling of $\mathrm{Al} / \mathrm{SiC}$ metal matrix composite, where roughness increases as cut feed rate increased. Tracing the values of the contour plots against the values of feed rate and the surface roughness, one can note that the MQL environment has a finer surface than that of the dry condition.

\section{Effects of spindle speed and axial depth of cut on surface roughness}

Figures 6 and 7 show the surface roughness contour plot for spindle speed versus the axial depth of cut for dry and 


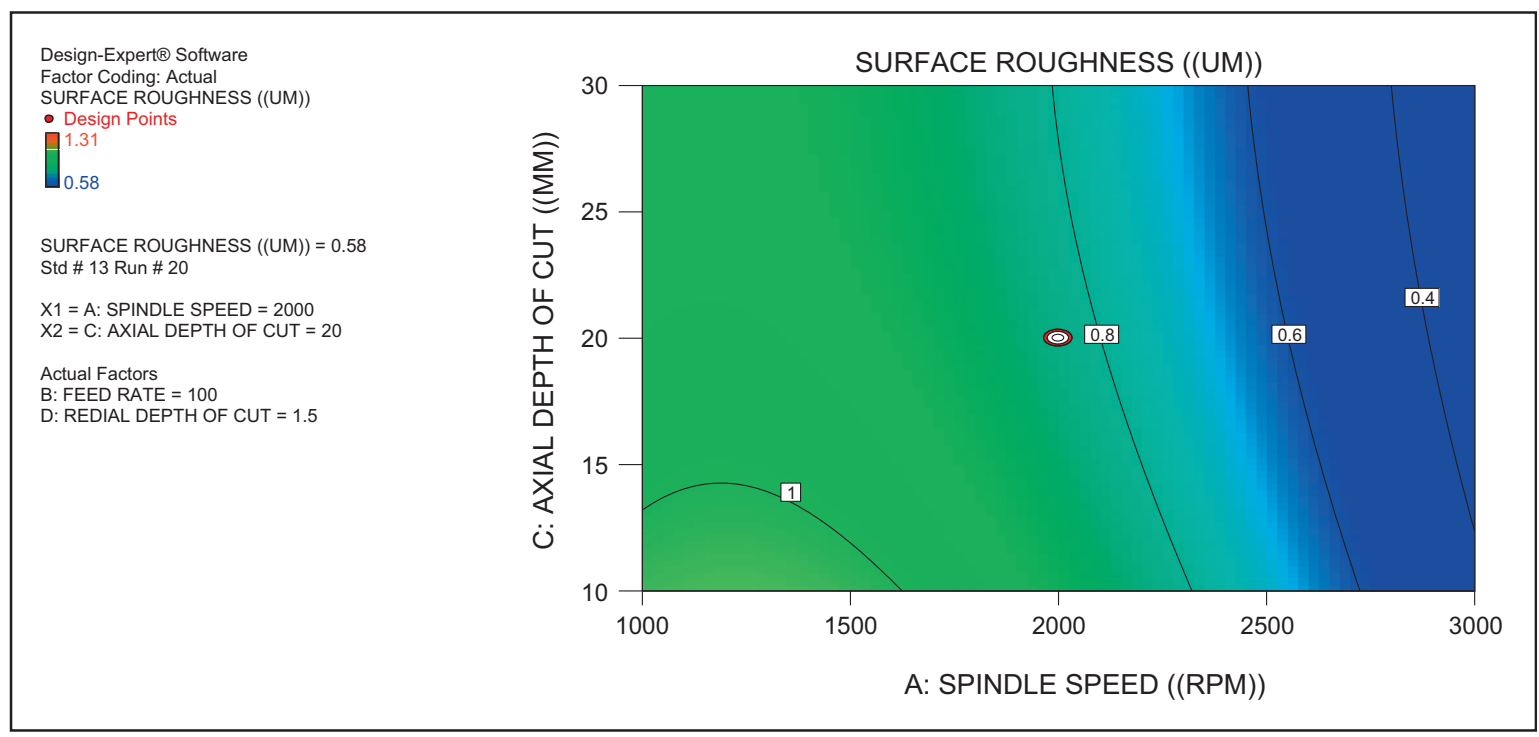

Figure 6. Surface roughness contour plot for spindle speed vs. axial depth of cut in dry condition.

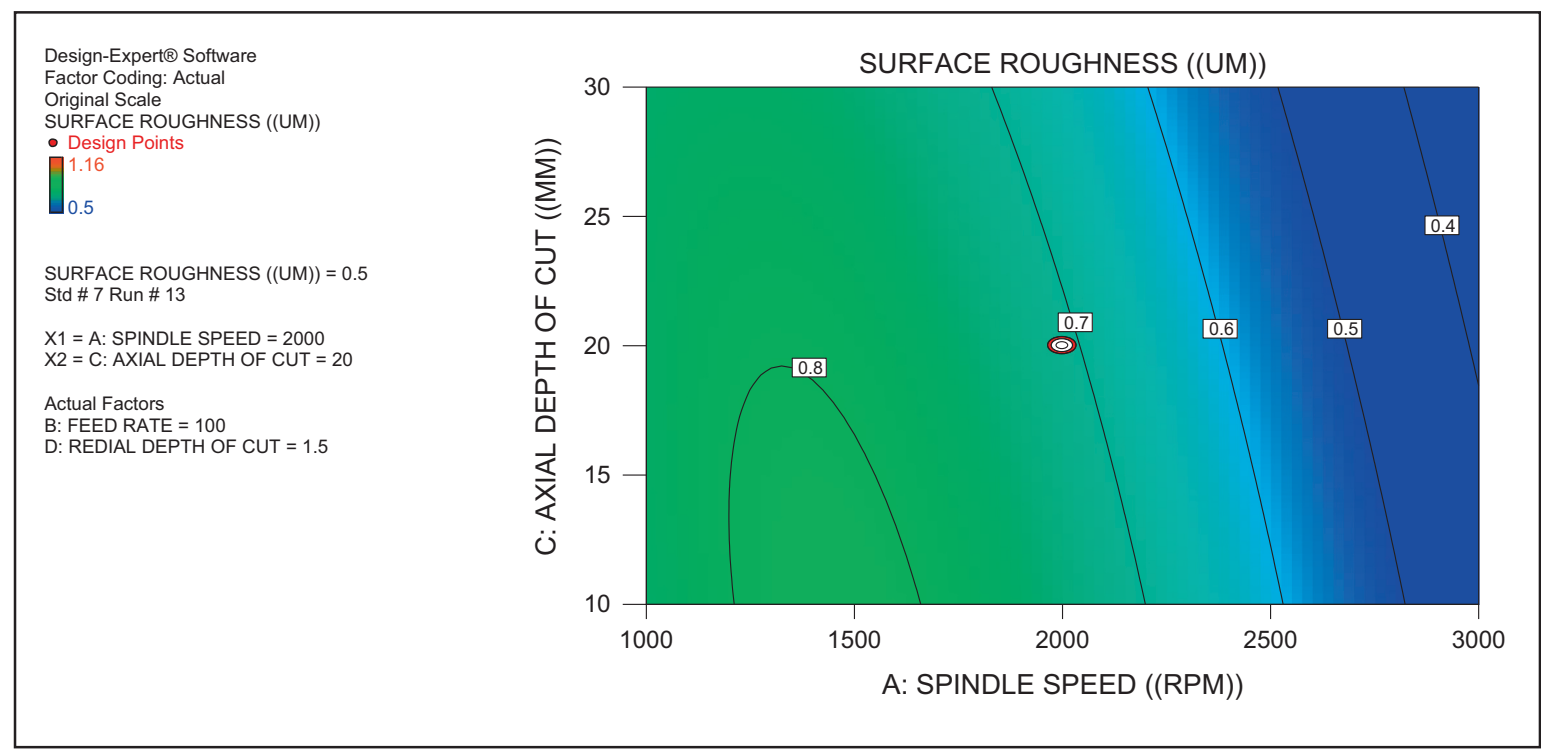

Figure 7. Surface roughness contour plot for spindle speed vs. axial depth of cut in MQL condition.

MQL conditions, respectively. At each instance, the feed rate and radial depth of cut are kept at $100 \mathrm{~mm}$ and $1.5 \mathrm{~mm}$, respectively. It can be clearly seen that the spindle speed has more impact when compared with the axial depth of cut when the color variation and contour lines are studied. At higher spindle speed, the surface roughness was greatly reduced even when the axial depth of cut was increased.

On the other hand, it was observed that the surface roughness witnessed under dry condition was far more especially using low spindle speed compared with that of the MQL condition. Specifically, at spindle speed of $2000 \mathrm{rpm}$ and feed rate of $20 \mathrm{~mm} / \mathrm{min}$, the surface roughness obtained during dry condition was $0.58 \mu \mathrm{m}$ while that for the MQL condition was $0.50 \mu \mathrm{m}$.

\section{Effects of the feed rate and axial depth of cut on surface roughness}

Figures 8 and 9 show the surface roughness contour plot for the feed rate and axial depth of cut for dry and MQL conditions, respectively. At each instance, the spindle speed and radial depth of cut are kept at $2000 \mathrm{rpm}$ and $1.5 \mathrm{~mm}$, respectively.

Studying the contour lines of Figures 8 and 9, one can clearly notice that the feed rate has more impact than the axial depth of cut. At low feed rate, the surface roughness was very small notwithstanding the variation of the axial depth of cut. However, as the feed rate increases, it deteriorates the surface finish. This result was also in line with the work done by Adeel et al. [18] where their result shows that surface roughness 


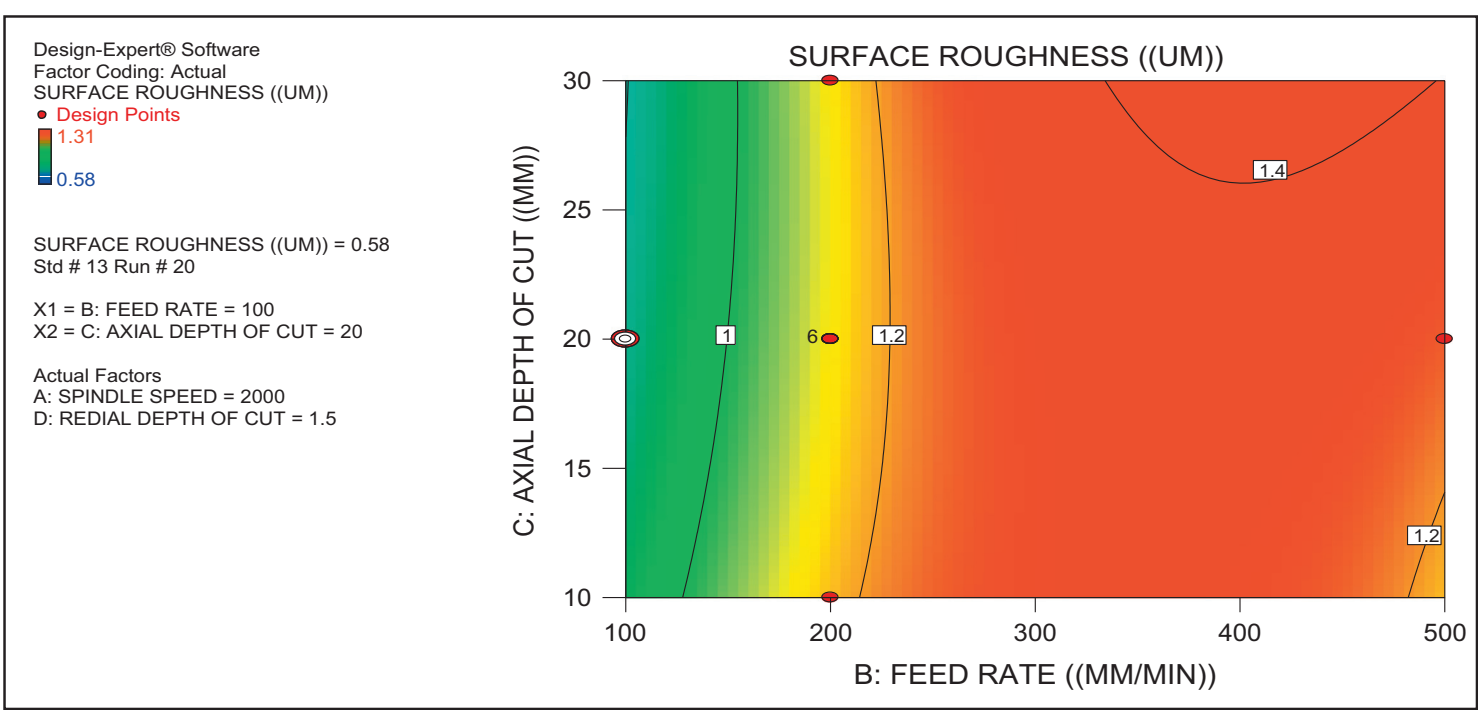

Figure 8. Surface roughness contour plot for feed rate vs. axial depth of cut in dry condition.

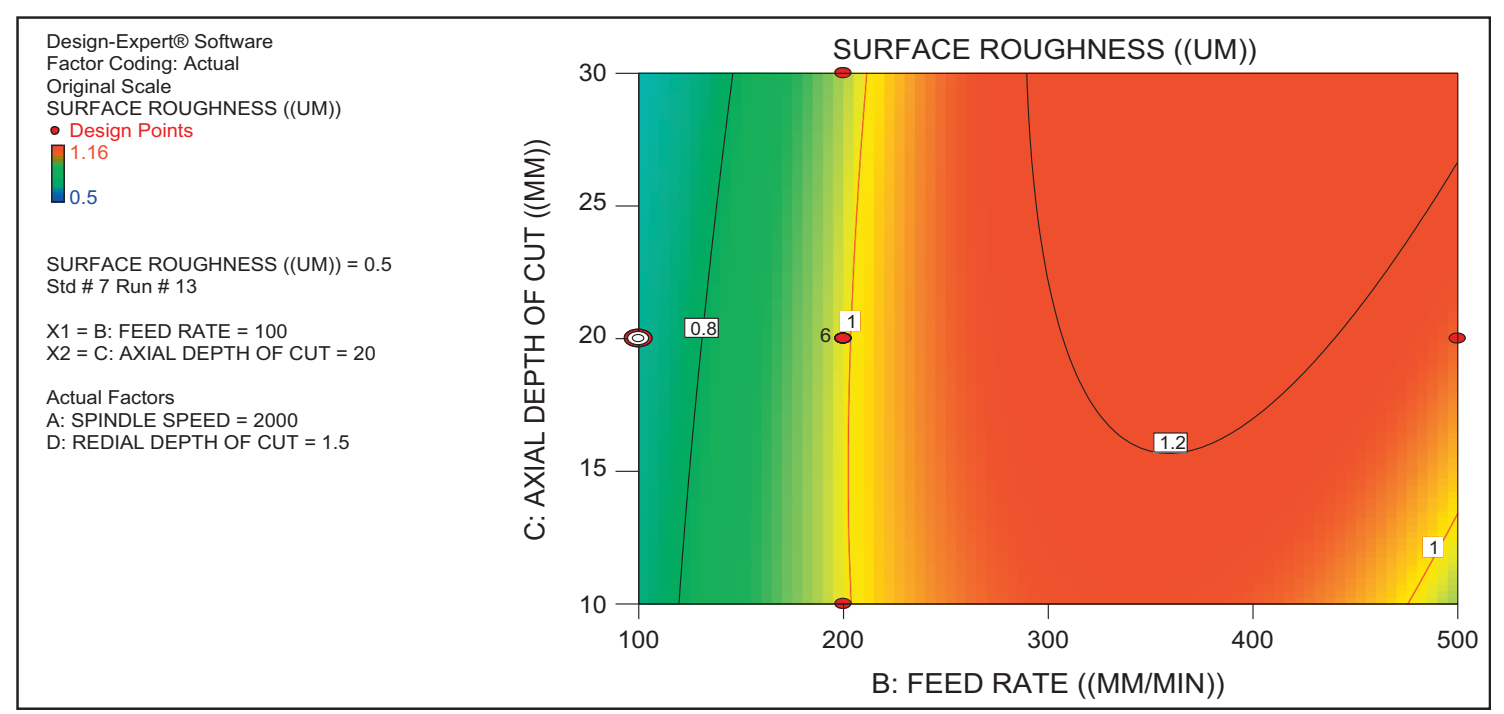

Figure 9. Surface roughness contour plot for feed rate vs. axial depth of cut in MQL condition.

values increase as the feed rate is increased. The above scenario occurs for both MQL and dry conditions. On the other hand, at a higher feed rate and lower axial speed, the surface roughness reduces, which perhaps may be as a result of reduction in vibration. However as the axial depth of cut is increased, maintaining the same feed rate, the roughness surfaces again.

\section{Effects of the feed rate and radial depth of cut on surface roughness}

Figures 10 and 11 show the surface roughness contour plot for the feed rate and radial depth of cut for dry and MQL conditions, respectively. At each instance, the spindle speed and radial depth of cut are kept at $2000 \mathrm{rpm}$ and $20 \mathrm{~mm}$, respectively.

It is essentially noted that just like in the case of the feed rate versus the axial depth of cut, in which the depth of cut has more impact on the surface roughness. In the case of radial depth of cut, the feed rate also has more impact on the surface roughness.

\section{Effect of axial depth of cut and radial depth of cut on surface roughness}

Figures 12 and 13 show the surface roughness contour plot for axial depth of cut versus radial depth of cut for dry condition and MQL condition, respectively. At each instance, the spindle speed and the feed rate were kept constant at $2000 \mathrm{rpm}$ and $100 \mathrm{~mm}$, respectively.

Comparing the impacts caused by the spindle speed and feed rate, it was found that both the axial depth of cut and radial depth of cut have less impact, with the axial depth of cut being the least. This trend corresponds with the one obtained by Arokiadass et al. [13] where he also concluded that 


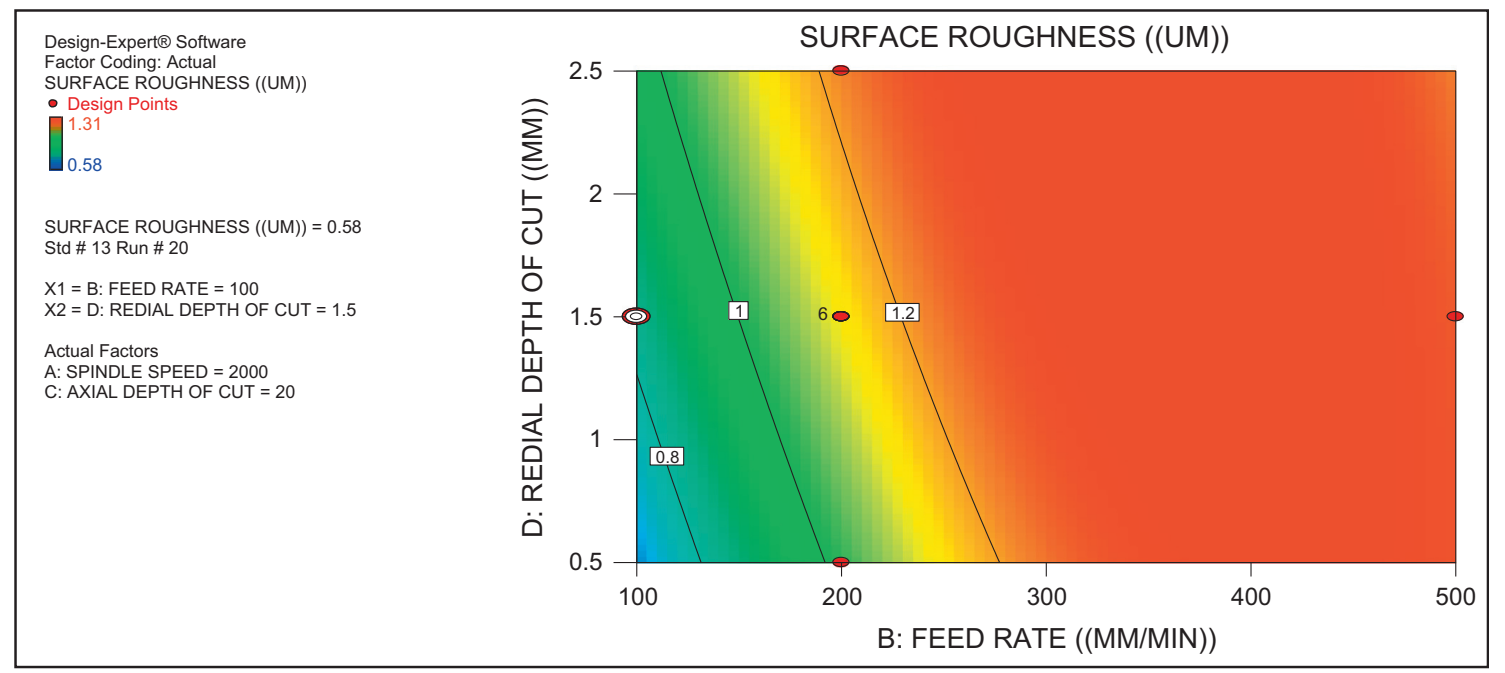

Figure 10. Surface roughness contour plot for feed rate vs. radial depth of cut in dry condition.

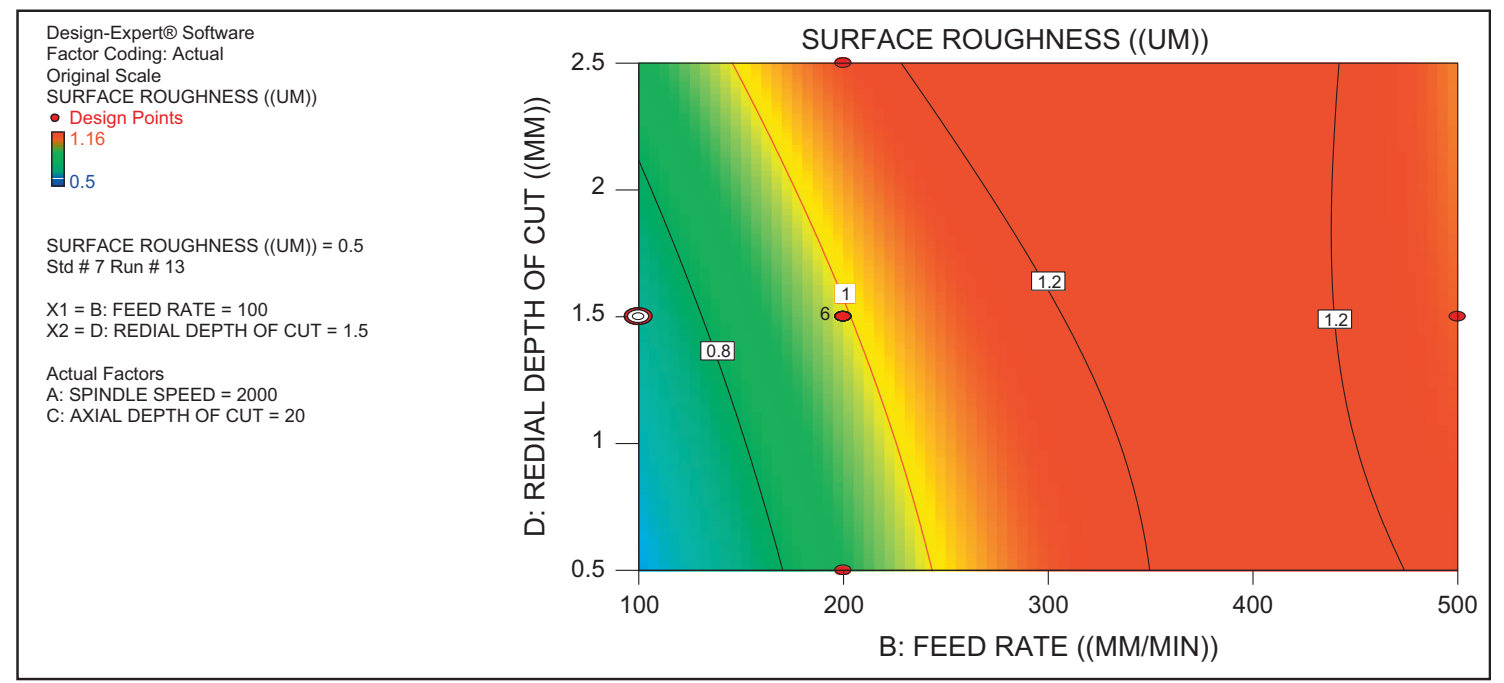

Figure 11. Surface roughness contour plot for feed rate vs. radial depth of cut in MQL condition.

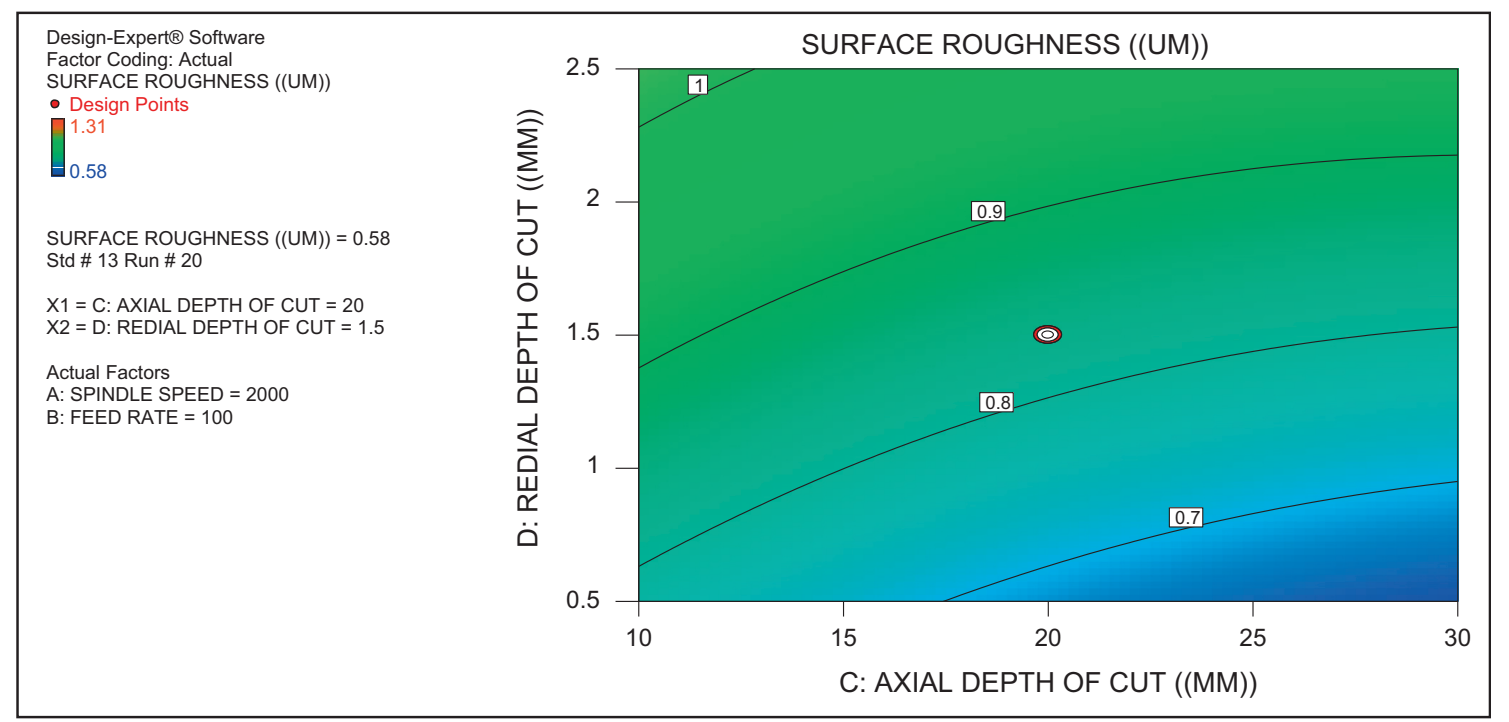

Figure 12. Surface roughness contour plot for axial depth of cut vs. radial depth of cut in dry condition. 


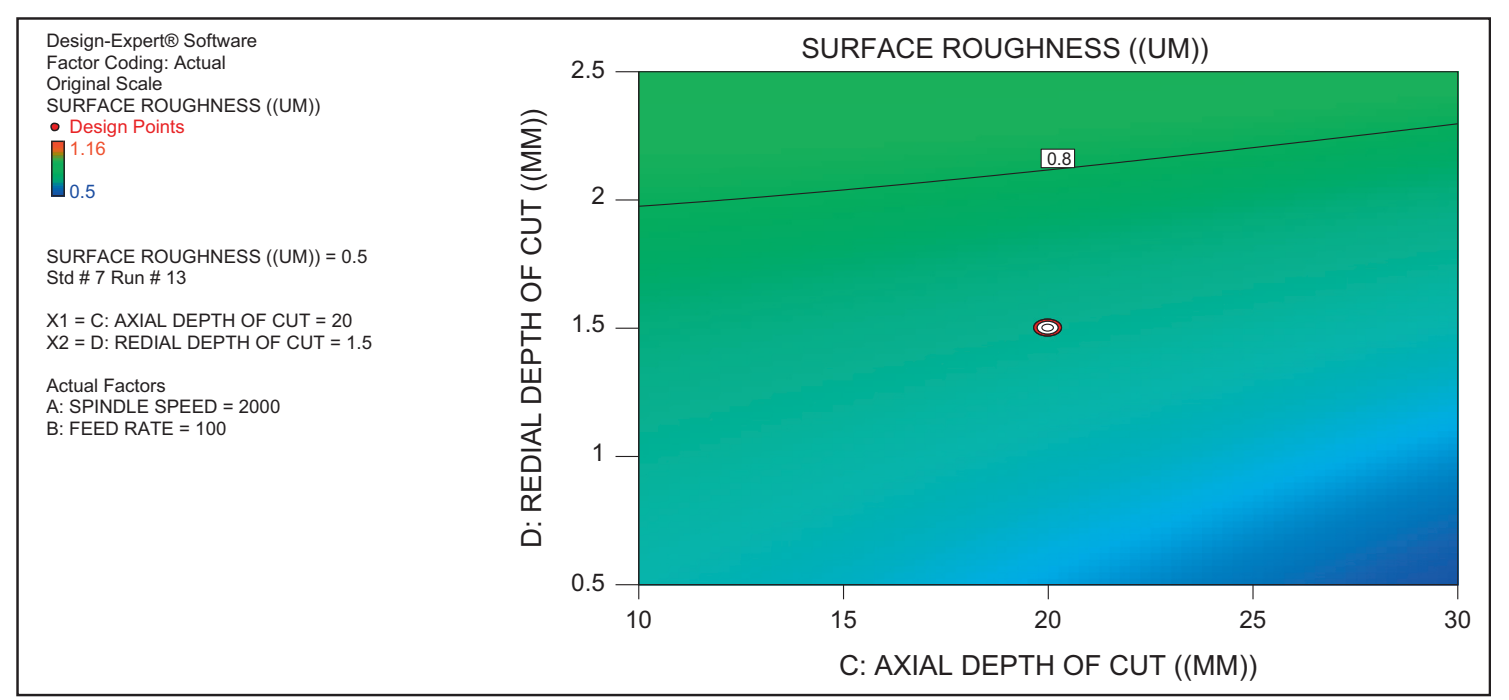

Figure 13. Surface roughness contour plot for axial depth of cut vs. radial depth of cut in MQL condition.

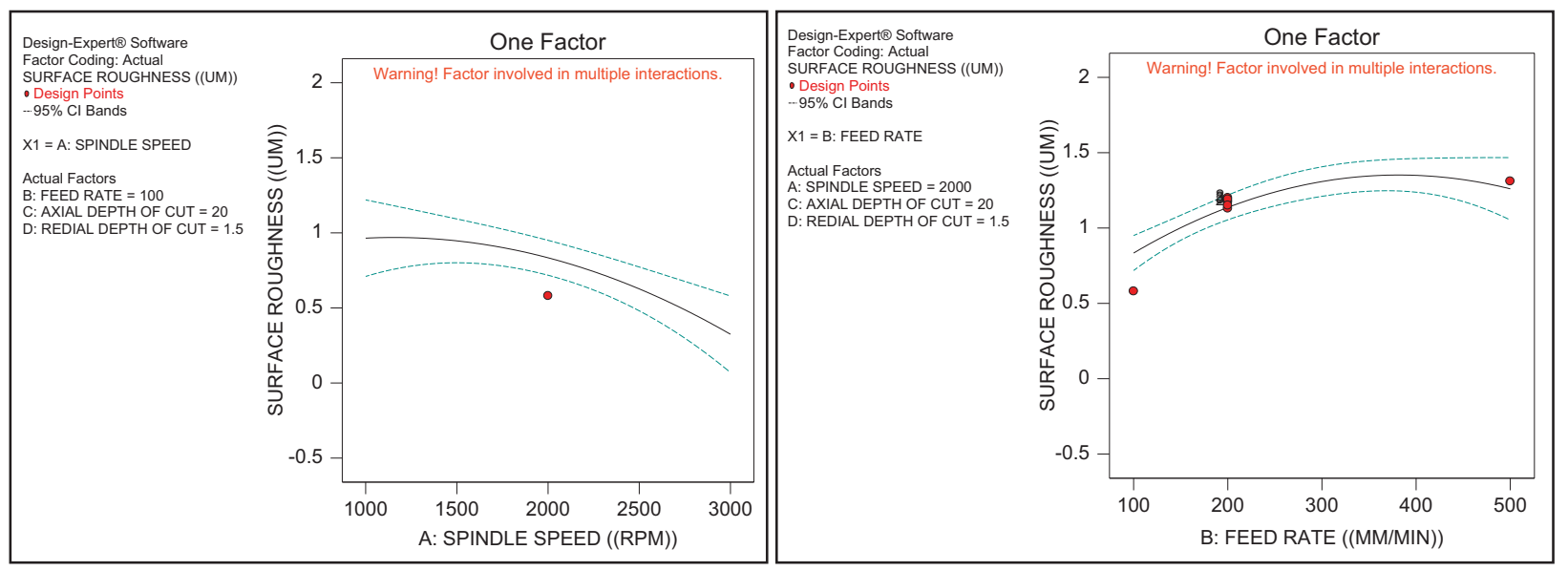

Figure 14. Effects of spindle speed on surface roughness as one factor and feed rate on surface roughness as one factor.

the depth of cut has minimal effect on surface roughness, even though he did not distinguish the depth of cut in question.

The trend of this variation in surface roughness is the same in both dry and MQL conditions but of course deterioration of surface roughness for dry condition than it was with the MQL. This is because the frictional effect is reduced due to the lubrication at the work piece and tool interface. This is in line with model created for both dry and MQL condition where depth of cut has least influence on surface roughness. This is in line with model created for both dry and MQL condition where radial depth of cut has less influence on surface roughness.

\subsection{One factor effects of spindle speed and feed rate}

It was noted that the spindle speed and feed rate have more impact than the rest. The effects that each has based on the levels adopted for each parameter in this research were shown in Figure 14. It clearly shows that increasing the spindle speed reduces the surface roughness while increasing the feed rate does the opposite (i.e. increases the surface roughness).

\section{Conclusions}

Experimental works have been carried out on aluminium 6061 in two different environments, namely; dry and MQL environments. A comparison of the effects of cutting parameters in dry and MQL environments on the surface roughness was made. Surface roughness values for MQL condition were lower with up to $20 \%$ reduction when compared to dry conditions. MQL cutting condition was found to be best and more reliable condition because it is environmentally friendly and gives better surface finish. The important conclusions drawn from the research are summarized as follows:

- From the experimental values of Table 5, the optimum or minimum surface roughness during cutting process occurs at spindle speed of $2000 \mathrm{rpm}$, feed rate of $100 \mathrm{~mm} / \mathrm{min}$, axial depth of cut $20 \mathrm{~mm}$ and radial depth 
of cut $1.5 \mathrm{~mm}$. For this condition, the minimum surface roughness was $0.58 \mu \mathrm{m}$ for dry and $0.50 \mu \mathrm{m}$ for MQL environments.

- Spindle speed and feed rate as independent factors have the most influence on the surface roughness. However, while increase in the spindle speed increases the surface roughness, that of the feed rate reduces it. This was clearly depicted in Figure 14. Similarly radial depth of cut has little effect on the surface roughness and axial depth of cut has no significant effect on the surface roughness.

- Interaction effects between spindle speed and feed rate also possesses a major effect over the surface roughness, followed by axial depth of cut and radial depth of cut.

\section{References}

1. U.C. Okonkwo, C.O. Osueke, C.A.K. Ezugwu, Minimizing machining time in pocket milling based on optimal combination of the three basic prescription parameters, International Research Journal of Innovative Engineering 1 (2015) 12-34.

2. T. Matsubara, H. Yamamoto, H. Mizumoto, Study on accuracy in end mill operations, Bulletin of the Japan Society of Precision Engineering 21 (1987) 95-100.

3. E. Budak, Y. Altintas, Peripheral milling conditions for improved dimensional accuracy, International Journal of Machine Tools \& Manufacture 34 (1994) 907-918.

4. T. Insperger, J. Gradišek, M. Kalveram, G. Stépán, E. Govekar, Machine tool chatter and surface location error in milling processes, Journal of Manufacturing Science and Engineering 128 (2006) 913.

5. M. Field, J.F. Kahles, W.P. Koster, Surface Finish and Surface Integrity, ASM Handbook, vol. 16, Machining, 9th edn., ASM Publication, ASM, Metal Park, Ohio, 1989.

6. G. Peigne, H. Paris, D. Brissaud, A. Gouskov, Impact of the cutting dynamics of small radial immersion milling operations on machined surface roughness, International Journal of Machine Tools \& Manufacture 44 (2004) 1133-1142.

7. H.A. Kishawy, M.E. Dumitrescu, M.A. Elbestawi, Effect of coolant strategy on tool performance chip morphology and surface quality during high-speed machining of A356 aluminum alloy, International Journal of Machine Tools \& Manufacture 45 (2005) 219-227.

8. A.L. Mantle, D.K. Aspinwall, Surface integrity of a high speed milled gamma titanium aluminide, Journal of Materials Processing Technology 118 (2001) 143-150.

9. M.Y. Wang, H.Y. Chang, Experimental study of surface roughness in slot end milling, International Journal of Machine Tools \& Manufacture 44 (2004) 51-57.

10. Y.H. Tsai, J.C. Chen, S.J. Lou, An in-process surface recognition system based on neural networks in end milling cutting operations, International Journal of Machine Tools \& Manufacture 39 (1999) 583-605.

11. Y.M. Ertekin, Y. Kwon, T.L. Tseng, Identification of common sensory features for the control of CNC milling operations under varying cutting conditions, International Journal of Machine Tools \& Manufacture 43 (2003) 897-904.

12. T.L. Ginta, A.K.M. Nurul Amin, H.C.D. Mohd Radzi, M.A. Lajis, Development of surface roughness models in end milling titanium alloy Ti-6Al-4V using uncoated tungsten carbide inserts, European Journal of Scientific Research 28 (2009) 542-551.

13. R. Arokiadass, K. Palaniradja, N. Alagumoorthi, Predictive modeling of surface roughness in end milling of $\mathrm{Al} / \mathrm{SiCp}$ metal matrix composite, Archives of Applied Science Research 3 (2011) 228-236.

14. I.P. Okokpujie, U.C. Okonkwo, Effects of cutting parameters on surface roughness during end milling of aluminium under minimum quantity lubrication (MQL), International Journal of Science and Research 4 (2015) 2937-2942.

15. L.B. Abhang, M. Hameedullah, Experimental investigation of minimum quantity lubricants in alloy steel turning, International Journal of Engineering Science and Technology 2 (2010) 3045-3053.

16. N. Tosun, M. Huseyinoglu, Effect of MQL on surface roughness in milling of AA7075-T6, Materials and Manufacturing Processes 25 (2010) 793-798.

17. I. Korkut, M.A. Donertas, The influence of feed rate and cutting speed on the cutting forces, surface roughness and tool-chip contact length during face milling, Materials \& Design 28 (2007) 308-312.

18. A.H. Suhail, N. Ismail, S.V. Wong, N.A. Abdul Jalil, Optimization of cutting parameters based on surface roughness and assistance of workpiece surface temperature in turning process, American Journal of Engineering and Applied Sciences 3 (2010) 102-108.

Cite this article as: Okonkwo UC, Okokpujie IP, Sinebe JE \& Ezugwu CAK: Comparative analysis of aluminium surface roughness in end-milling under dry and minimum quantity lubrication (MQL) conditions. Manufacturing Rev. 2015, 2, 30. 